DOC.

D101.60/4:

1115

Iecnnical Report 1115

\title{
Applying Digital Technologies to Evaluation: A Focus on Command and Control
}

Carl W. Lickteig and Kathleen A. Quinkert

U.S. Army Research Institute

June 2001

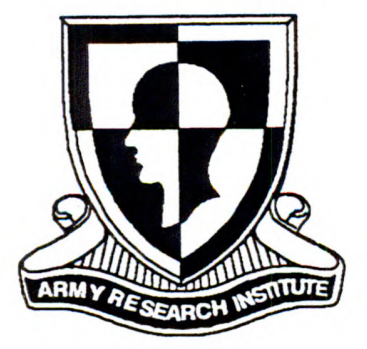

United States Army Research Institute for the Behavioral and Social Sciences

Approved for public release; distribution is unlimited. 